\title{
Sustaining Training Quality in Technical and Vocational Colleges of Oromia Regional State, Ethiopia
}

\author{
Birhane Sime Geressu (Assistant Professor) \\ School of Educational Sciences and Technology Teacher Education, \\ Adama Science and Technology University, P.O.Box 1526 or 1888, Ethiopia, \\ E-mail: birhane_200@yahoo.com alternative birhanesime2012@gmail.com
}

\section{Doi:10.5901/mjss.2014.v5n10p342}

\begin{abstract}
The intent of this paper was to examine the extent of the sustainability of training quality in TVET Colleges of Oromia Region, Ethiopia. To achieve this purpose, researcher used concurrent triangulation mixed approach research paradigm. The participants of the study include: 71 trainers; 81 trainees and 85 graduates. Moreover, 15 College Deans, 15 District, 6 Administrative Zones and 2 Regional TVET agencies were purposely selected and included in the study. To this end three different but complementary instruments: Questionnaires, semi-structured interviews and document analysis were employed to solicit data from key informants in the study setting. Data were analyzed both through qualitative and quantitative analysis methods. The study result showed that lack of adequate and relevant labour market information, training need assessment, tracer study results, practical competence of leaders and trainers and weak participation of stakeholders affects the sustainability of the training quality in TVET Colleges. Hence, to transfer relevant technical skills the study recommends the importance of enhancing the competence of leaders' and trainers through education and training. Besides, participation of stakeholders in designing, implementing and formulating internal quality assurance system is binding to sustain training quality in TVET Colleges.
\end{abstract}

Keywords: sustainability, training, quality, TVET, leaders, trainers, stakeholders', participation

\section{Introduction}

The concept quality is difficult to define and measure as it means different things to different people. Some people define quality in relation to the purpose of the product or service. Others define as a fulfillment of expectation. Still most people use the word to mean having a high degree of excellence. This indicates that the concept of quality is relative, subjective and variable. Besides, the phrase quality education is even more difficult to define and measure. As a result, various scholars have attempted to define educational quality differently. For instance, Peters and Waterman (1982) defined quality as excellence in education. For Parasuraman, Zeithaml and Berry (1985) quality is meeting or exceeding customer's expectations of education. Similarly, Juran and Gryna (1988); Okebukola (2005) defines quality of education as fitness of educational outcome and experience for use.

According to Roschanski (2007) the quality and sustainability of education and training can be influenced by quantity and quality of inputs and processes. For the writer out of many inputs the major input that determines the quality of education and training is the quality of trainer because effective teaching requires individuals who are academically able, technically competent and having command of the subject they are required to teach (Brameld, 1972). According to Tippelt and Antonio (2003) technical competence refers to assimilation of cognitive capabilities and motor skills inherent to an occupation. For Aggrawal (2004) technical competence is the ability and willingness of trainers to apply skills and knowledge acquired during the vocational training. GTZ (2000) on the other hand, described different types of technical competence of trainers that comprises demonstration of practical skills; use of technology, resource and other work tools of the occupational areas. The content of the curriculum and its relevance to the needs of the learners and the society, the learning environment and material resources that facilitate effective training in centers are also important elements that determines training outcomes (Jaiyeoba \& Atanda, 2005).

According to UNESCO (2003) TVET is considered as an important element in human resource development with the general objective of preparing learners with adequate knowledge and skills for life and the labor market. To achieve these intended objectives TVET providers should establish effective partnerships with stakeholders, in designing and building education and training system found in the labor market. Besides, TVET providers should develop institutional mechanism that will ensure the establishment of an excellence of instruction and the development of employment-linked 
competencies amongst graduates. Moreover, financing mechanisms for the respective skills for employment will also be developed collaboratively between the public and private sectors.

On top of this ILO (2001) states that vocational training has a direct impact on the productivity of an enterprise. Therefore vocational training cannot be designed without taking into account the real needs, standards and concerns of the industrial sectors and the decent work requirements of the training recipient in areas such as the quality, level and certification, attendant effect of training on wages promotion and task allocation.

The employers have also a direct role to play in the provision of vocational training since they are the major beneficiaries. Besides, they can participate by direct financing, provision of facilities and trainers. In the case of firmspecific skills requirements, it is the responsibility of the employer to train or finance the training of its staff. Employers can contribute more significantly to decent work by establishing apprenticeship programmes especially to alleviate youth unemployment, by promoting entrepreneurship among young persons, by supporting research for job creation especially regarding the vulnerable groups, by sharing expertise with and advising Governments and by promoting Governments' skills-related programmes to other employers (UNESCO, 2002). The other factor that may determine the sustainability of TVET trainings is quality and competence of leadership. As it was clearly stated in qualifications framework for TVET Leaders and Trainers (TLTQF) TVET leader are considered as a management position of TVET institution for the overall TVET activities that includes training, technology accumulation and transfer and dealing with administrative issues within the entire TVET institution (MoE, 2010).

However, from the researcher personal experience and informal discussion made with Oromia Region TVET agency experts, in the existing 18 TVET Colleges that there is no well-established mechanism that enables them to maintain training quality in their respective Colleges. Moreover, as planning and delivery of training programs were not based on the result tracer study, assessment of the need of trained workforce in the labour market and collaboration with concerned stakeholders the effectiveness of the training being offered was already under question (NITCH, 2010). Because, basically, the effectiveness of training depends on the extent to which trained workers use their skills in employment (Middleton, Ziderman and Adams, 1996). Hence, investigating the extent of the sustainability training quality in TVET Colleges in relation with the skills needed in the labour market is helpful to take timely remedial action.

Moreover, to address the aforementioned problem, the study was guided by the following basic research questions: (1) To what extent TVET Colleges in Oromia using required inputs to sustain training quality in the Region? (2) What are the major challenges associated with the sustainability of quality training in Oromia TVET Colleges? Finally, the output of this research may create awareness among policy maker and implementers to scrutinize the extent of the sustainability of quality training and to deal with major problems that affects the sustainability of quality training in all TVET Colleges located in Oromia Region, Ethiopia.

\section{Research Methodology}

The choice of methodology for a study is mostly based on the purpose of the study and the research question. In this regard, the empirical investigation is based on the mixed approach research paradigm; predominantly on the concurrent nested strategy. This is evidenced by Creswell (2009) who states that mixed method helps to triangulate qualitative and quantitative data sources and provides a better, more substantive picture about the topic understudy. Moreover, stressing the advantage of mixed approach, he also stated that using this approach allows a researcher to obtain a variety of information on the same issue, use the strength of each approach to overcome the deficiencies of others, and achieve a higher degree of validity and reliability. Specifically, the quantitative method employed for the study was cross-sectional descriptive survey method. This is because; the method enables the researcher to describe how TVET Colleges can sustain their training quality to achieve their objectives. For the reason of manageability, the study was delimited to inputs to quality training, such as: trainers' academic and technical competence, participation of stakeholders and factors affecting the sustainability of quality training in TVET Colleges.

The target population of this research comprises 71 (21.3 percent) trainers', 81 (23.2 percent) 2012/13 Level III trainees and 85 (27.8 percent) Level III graduates were included in the study. Besides, 15 Deans, 15 District, 6 Administrative Zone and 2 Regional TVET agency process owners were purposely selected and interviewed. The tools used to gather relevant data from the research participants were questionnaire, in-depth semi-structured interviews, and relevant document analysis. Finally, the raw data collected through a quantitative approach was tallied, tabulated, and analyzed by using grand mean and one way ANOVA, percentage and chi-square. On the basis of data analysis findings were generated, conclusions were drawn and workable recommendations were forwarded. Moreover, the qualitative data collected from the interviews and document analysis was first read from notes by the researcher and then categorized. Finally, data was analyzed with the help of themes to view a clear picture of the issue under study. 


\section{Results and Discussions}

Teaching practical skill is very different from teaching knowledge or theory and it requires some special considerations. Since TVET basically emphasizes on practical training and imparting skills for trainees, trainers must have experiences, adequate practical skills and should provide students with occupational skills and competencies desired in the world of work (MoE, 2010). With this concept different questions were forwarded to respondents and obtained results are tabulated in Table 1 below

Table 1: Trainers technical and academic competencies

\begin{tabular}{|c|l|c|c|c|c|}
\hline \multirow{2}{*}{ No } & \multicolumn{2}{|c|}{ items } & \multicolumn{2}{c|}{ Grand Mean } & \multicolumn{2}{c|}{ ANOVA } \\
\cline { 3 - 5 } & & Mean & SD & F & P-value \\
\hline 1 & practical competence & 1.45 & 0.82 & 6.456 & 0.002 \\
\hline 2 & Skill to operate machines, tools, equipment & 1.48 & 0.82 & 2.459 & 0.087 \\
\hline 3 & maintenance and repairing skill & 1.36 & 0.55 & 4.142 & 0.017 \\
\hline 4 & ICT or Computer skills & 1.56 & 0.80 & 51.168 & 0.000 \\
\hline 5 & knowledge in the subject they are training & 3.67 & 0.79 & 4.805 & 0.009 \\
\hline 6 & Pedagogical knowledge & 2.83 & 0.93 & 3.263 & 0.040 \\
\hline 7 & Psychological knowledge & 1.39 & 0.60 & 36.508 & 0.000 \\
\hline
\end{tabular}

Mean $\leq 2.00$ low; mean 2.01-2.50 average; mean 2.51-3.00 high

As the data in Table 1, reveals in item 1, majority of respondents rated that trainer's proficiency in practical skills as low. The grand mean (1.45) shows that how the current TVET trainees suffer from inadequacy of practical skills. The unanimity of the respondents indicates that the dimension of the problem. Apparently, this implies trainers were not in a position to offer the required skills for the level.

For TVET trainers competency in machine operation and relevant equipments is not a matter of option but obligatory. However, the vast majority of respondents ascertained that the trainers' proficiency in manipulation and operation of machines was significantly low (grand mean $=1.48$ ). Contrary to what was initially expected, respondents reacted negatively. This finding is consistent with survey of Edukans (2012) which pointed out that were not serving the training because trainers and workshop personnel were unable to operate them properly. They were simply placed in the shops." He even indicated some of the machines have never been in use since their installation. The interviewee response of District, administrative Zone TVET heads and regional experts also affirmed the above finding. They asserted a trainer skill in operation of machine is low.

Item 3 of Table 1 treats trainers' ability in maintenance and repairing of machines and other training tools. All respondents affirmed that trainers' competency in maintenance and repair was also below the average (1.36). The study of Edukans (2012) on TVET also pointed out most machines were in a poor state and not functioning due to damage and breakage. Thus, one can possibly conclude that TVET is handicapped not only by the scarcity of appropriate training tools and machines but also by the absence of proper maintenance and repair for training materials.

ICT is an important tool for enhancing access and quality in TVET. Through ICT, teaching materials can be provided at a lower cost. In accordance with this view respondents were asked to rate ICT skills TVET trainers and to what extent they employed it for the improvement of their training undertakings. The vast majority of respondents replied trainers' ability in computer/ICT was low. This is also unpleasant result because TVET institutions themselves provide ICT training and also had better access to technologies. Another item dealt with trainers' performance in developing training materials and teaching aids. Still the result of the mean of responses shows that trainers' ability in developing training materials was below average. The ANOVA test result revealed that there was a statistically significant perception difference among the respondents except for item 2, in all five cases P-value is less than 0.05 . The result of multiple mean comparisons using Tukey's HSD showed that perception difference occurred between trainees on the one hand and trainers on the other. This dissimilarity may occur due to trainees' judgment, because they are unfamiliar with the most recent developments in TVET schools.

The long experience of trainers in the profession may also contribute to such differences in perception. With respect to item 2 in Table 1, however P-value is greater than $0.05(0.087)$ which disclosed that there was no statistically significant difference regarding trainers proficiency in manipulation and operation of machines and training tools. In general it is possible to conclude that trainers' competency in technical skills was significantly low and it is undeniable fact that absence of linkage with industries and theory-centered pre-service and in-service training soundly contributed to this 
drawback and prevalent problems.

Trainers/teachers have to be both knowledgeable in subject areas and skilful in a wide range of teaching approaches to carter for the diverse learning of every student (Clement, 2006). Having this in mind, item 1 was presented to respondents to rate whether trainers were adequately knowledgeable in their subject area. The result seems encouraging. As illustrated in Table 2, the substantial number of respondents with strong similarity rated that trainers subject matter knowledge was high (grand mean 3.67). Moreover, the majority of interviewee stated, unlike practical skills, trainers have adequate theoretical knowledge.

Besides, ANOVA test result confirmed that the existence of statistically significant perception difference among the respondents because P-value for the item is 0.009 which is below 0.05 . Tukey's HSD statistical analysis still shows the perception difference occurred between trainers on the one side and trainees on the other. This difference may occur due to trainers' proximity to the training activities and trainees unfamiliarity with some present developments in TVET.

In item 6 an attempt was made to examine trainers' knowledge of pedagogy. As depicted from Table 1, the vast majority of respondents indicated that trainers have adequate pedagogical knowledge and rated high. Moreover, ANOVA test result revealed that there is significant difference among the three groups on perception of trainers' subject knowledge and pedagogical areas. The perception difference for this item occurred between trainers and trainees. The perception difference can be attributed to differences in school capacity and the presence of qualified trainers in schools. The fact that some TVET institutions have more qualified trainers can contribute to such differences.

In item 7 of Table 1 respondents were asked on how trainers were psychologically knowledgeable and practioner. All respondents rated trainers psychological knowledge as low (grand mean =1.39). Further, the ANOVA test result indicates that there was statistically significant perception difference among the respondents because P-value for this item (0.000) is below 0.05. In sum, TVET trainers' psychological knowledge was unsatisfactory. The Tukey's HSD multiple mean comparisons reveals that the perception difference occurred between trainers on the one hand and trainees on the other hand. Such differences may occur due to less knowledge and understanding that students have on the specifications and such technical matters. In general, from the above discussion, one can possibly conclude that trainers' ability was low both in psychology and specification of machines and other training materials.

Likert type scale (low=1, medium =2, high=3) was used to assess the participation level of the stakeholders in planning, providing the vocational and guidance service, resource allocation, providing information that help to adjust the TVET curriculum program management, paying pocket money for the trainees and monitoring and evaluating in TVET institutions. Based on this, the average mean values below 1.50 was taken as low , 1.51-2.50 medium and above 2.5 high .In this regard, the extent of stakeholder, participation was rated by respondents as indicated here under.

Table 2: Stakeholders Participation

\begin{tabular}{|c|l|c|c|c|}
\hline \multirow{2}{*}{ No Items } & \multicolumn{3}{|c|}{ Grand Mean } \\
\cline { 3 - 5 } & & Mean & SD & F \\
\hline 1 & Planning the training programmes & 1.30 & 0.61 & 1.980 \\
\hline 2 & Providing vocational and guidance service & 1.46 & 0.74 & 1.959 \\
\hline 3 & financing the training programme & 1.40 & 0.70 & $2.759^{\star}$ \\
\hline 4 & Providing the training facilities & 1.45 & 0.74 & $2.588^{\star}$ \\
\hline 5 & Monitoring training standards & 1.44 & 0.73 & $2.743^{\star}$ \\
\hline 6 & Identifying training needs & 1.31 & 0.63 & 1.375 \\
\hline 7 & designing the training system & 1.30 & 0.61 & 1.319 \\
\hline 8 & training of trainers & 1.39 & 0.65 & $3.016^{\star}$ \\
\hline 9 & providing information that help to adjust the TVET curriculum & 1.40 & 0.70 & 1.355 \\
\hline 10 & paying pocket money for the trainees & 1.37 & 0.63 & 1.233 \\
\hline
\end{tabular}

As indicated in Table 2 above items 1-10, in TVET institutions the participation level of stakeholders was rated low with the average mean value less than 1.5. This shows that there was almost no participation of production or service rendering organizations, non-government organizations and private organizations in the overall TVET system.

The effectiveness of the TVET programme implementation depends on the managerial capacity of the institution. Nowadays, the participatory management is seen as the best method of management where the concerned stakeholders take part in managing, monitoring and evaluating the training programs. Interviewees also confirmed that the participation rate of the stakeholders who participated in programme management and monitoring and evaluating in TVET institutions were largely from the training institutions themselves and from government organizations. The comparison of mean was 
also computed using one-way ANOVA. The result showed that there was statistically significant difference among respondent groups on the response given to four variables. Those are, financing the progrmme, providing the training facilities, monitoring the training standards and in training of trainees.

Quality TVET is expensive as it needs a relatively low trainee/ trainer ration, workshops of reputable standards, regular investment in new equipment, quality trainers and leaders, and the maintenance and repair of existing equipment. Without adequate funding, commitment of stakeholders maintaining the quality of training fails under question. Concomitant with this question related to factors hindering the sustainability of quality training in TVET Colleges were posed to informants and the following results are obtained.Table 3: Factors Hindering the Sustainable Quality of Training

\begin{tabular}{|c|l|c|c|c|c|c|}
\hline \multirow{2}{*}{ No. Items } & \multicolumn{2}{|c|}{ Yes } & \multicolumn{2}{c|}{ No } & \multirow{2}{*}{ X $^{2}$} \\
\cline { 3 - 6 } & & No. & $\%$ & No. & $\%$ & \\
\hline 1 & $\begin{array}{l}\text { lablem of adapting the curriculum to the world of } \\
\text { Work }\end{array}$ & 130 & 54.9 & 107 & 45.1 & \multirow{2}{*}{0.845} \\
\hline 2 & More theoretical method of instruction & 126 & 53.2 & 111 & 46.3 & $14.822^{*}$ \\
\hline 3 & Lack of labor market information & 218 & 92 & 19 & 8.00 & 3.686 \\
\hline 4 & Lack of relevant training machines to local situation & 81 & 34.2 & 156 & 65.8 & 2.351 \\
\hline 5 & Lack of appropriate training machines/equipment & 88 & 37.13 & 149 & 62.87 & 4.142 \\
\hline 6 & Low Public Awareness toward TVET & 206 & 86.9 & 31 & 13.1 & $9.090^{*}$ \\
\hline 7 & Lack of tracer study & 185 & 78.1 & 52 & 21.8 & 1.693 \\
\hline 8 & Absence of training need assessment & 216 & 91.1 & 21 & 8.9 & 2.810 \\
\hline 9 & Shortage of training budget & 204 & 86.1 & 33 & 13.9 & $6.5 .01^{*}$ \\
\hline 10 & Shortage of training raw materials & 204 & 86.1 & 33 & 13.9 & $6.501^{*}$ \\
\hline
\end{tabular}

In Table 3, respondents were asked to rate the components of training programme which need high improvement. According to the response given by the respondents, the major problems that affect the development of market oriented and need based TVET programme were rated as follows. These were, the problem of adapting the curriculum to the world of work 130 (54.9 percent), more theoretical method of instruction 126 (53.2 percent), unavailability of labour market information 218 (92 percent), low public awareness toward TVET 206 (86.9 percent), low stakeholders participation 204 (86.1 percent), lack of tracer study 185(78.1 percent), absence of training need assessment 216 (91.1 percent) and shortage of training budget and raw materials 204 (86.1 percent). On the contrary, irrelevancy of training machines/equipment to local situation and inappropriateness of training machines/equipment to the continuous employability of the TVET graduate were rated 156 (65.8 percent) and 149 (62.87 percent) respectively.

\section{Conclusions}

The long term goal of TVET programme is to create a dynamic , responsive and efficient TVET system which is able to provide adequate and skilled technical and vocational human resources required to underpin the expanding economic development of the region and the country in large. To attain this goal, TVET plans should be designed to support the skills and knowledge needed by the individuals and rapid socio-economic growth of the region and the intended skilled manpower needed for employment. To do this TVET Colleges need to think how to progress the sustainability of quality training.

However, absence of training need assessment, lack of adequate and relevant labour market information, weak provision of vocational guidance service, concentrating on a restricted range of training programs, makes TVET system inefficient and irresponsive to labour market needs. Also, absence of independently organized institution that coordinate the collection of data on assessing the training need and labour market information and who analyze and supply the result for use makes the sustainability of quality TVET training unreliable.

But even more than this, evidence shows that the partnership between training institutions and stakeholders at all level in planning, resource allocation, provision of vocational guidance service, monitoring the training standard, identifying training needs, and in providing information that help to maintain the quality of training is low. On other hand, TVET institutions have inadequate internet services. Moreover, the training facilities such as size of school compound, size of workshops, libraries and stores were not as expected. Also, the training materials; machines, tools and equipment, computers, books, modules and raw materials for training were found to be better.

Moreover, the budget allocated for raw materials, machines and equipment, and project work was low. In brief, the analysis made showed that unavailability of labour market information, absence of training need assessment, problem of adapting the curriculum to the world of work, low stakeholders participation in TVET system, lack of sufficient budget for 
TVET training was among the problems that affects the sustainability of training quality in the study setting. To overcome the problems and to maintain the sustainability of training TVET Colleges need to arrange more practice time and do researches on the problem and evaluate their own graduates. Besides, appropriate and right kinds of training machines that are similar to the world of work one to be available in TVET Colleges. In addition, improving TVET-Industry linkage has to be one of the priority areas for action. Moreover, trainers themselves should make efforts to improve their own competencies and abilities.

\section{Acknowledgements}

I grateful to all informants that provide me adequate information and relevant documents

\section{References}

Aggrawal, J. C. (2004). Development and Planning of Modern Education. (8ed.). Delhi: Vakas Publishing House.

Brameld, T. S. (1972). Education as Power. New York: Holt, Rinehart and Winstong

Creswell, J.W. (2009). Research Design: Qualitative, quantitative and mixed methods approaches. (3rd ed) Los Angeles: SAGE Publications Inc.

Edukans Faundation (2012). TVET in Ethiopia. Addis Abab GTZ, (2000). Report on Vocational and Technical Training Structure: Recommendations and Future Perspective. Addis Ababa.

ILO (2001). Modernization in Vocational Education and Training in the Latin American and the Caribbean Region. Montevideo Juran, J.M. and Gryna, F.M. Jr (Eds) (1988). Juran's quality control handbook. New York: McGraw-Hill.

MoE (2010). Leaders and Trainers Framework. Addis Ababa, Ethiopia

Okebukola, P. (2005). Quality Assurance in the Nigerian University System. University of Jos, Nigeria Peters, T.J. and R.H. Waterman, (1982). Search of Excellence (1st. ed.), New York: Harper and Row.

Parasuraman, A., Zeithaml, V.A., and Berry, L.L.. (1985). SERVQUAL: a multiple-item scale for measuring consumer perceptions of service quality. Journal of Retailing, vol.64, no.1, Spring, pp.12-40.

Roschanski, H. (2007). Deprived Children and Education Ethiopia. Amsterdam. IREWOC

Tippelt, R. and Antonio A. (2003). Competency Based Training. Retrieved on March17,13 from http://www.inwent.org. UNESCO (2003).Strengthening the Industry Linkages with TVET programs in Arab Countries through sector partnership. Beirut UNESCO (2002). Technical and Vocational Education and Training for Twenty-first Century: Paris: UNESCO. 